\title{
Espías, rusos y maximalistas en el verano de 1919. La Semana Trágica revisitada desde las fuentes diplomáticas y periodísticas ${ }^{1}$
}

\section{Spies, russians and maximalists in the summer of 1919. The Tragic Week revisited from the diplomatic and journalistic sources}

\author{
Walter L. Koppmann ${ }^{2}$ \\ Sabrina Asquini ${ }^{3}$
}

\section{Resumen}

El artículo propone revisitar la Semana Trágica de 1919 en Buenos Aires a partir del análisis sobre las fuentes de la diplomacia y el espionaje extranjeros en el país, problematizando las perspectivas y la bibliografía existente. El relevamiento de materiales poco explorados habilitan la formulación de nuevos interrogantes sobre un tema aparentemente «agotado» respecto del cual, no obstante, recientes trabajos han demostrado que aún quedan diferentes aspectos por profundizar.

Palabras clave: Semana Trágica; espionaje; movimiento obrero; izquierdas.

\begin{abstract}
The aim of this paper is to revisit the Tragic Week of 1919 in Buenos Aires, analyzing new sources that belong from the foreign diplomacy and the espionage. In addition, it examines the mainstreamperspectives and bibliography.The little-explored documents enables new questions on an apparently already-known subject, with respect to which, however, recent works have shown that there are still different aspects to deepen.
\end{abstract}

Keywords: Tragic Week; espionage; labor movement; left wings.

\footnotetext{
1 Trabajo recibido el 19/03/2020. Aceptado el 30/06/2020.

${ }^{2}$ Centro de Estudios Históricos de los Trabajadores y las Izquierdas. Consejo Nacional de Investigaciones Científicas y Técnicas. Contacto: walter.koppmann@gmail.com

${ }^{3}$ Centro de Estudios Históricos de los Trabajadores y las Izquierdas. Consejo Nacional de Investigaciones Científicas y Técnicas. Contacto: sabrina.asquini@gmail.com
} 


\section{Introducción}

Los aniversarios de los acontecimientos históricos resultan momentos propicios para volver sobre ellos, tanto desde producciones periodísticas como historiográficas; lo cual, en ocasiones, habilita la emergencia de nuevos testimonios y/o perspectivas. Con motivo de un nuevo aniversario de la Semana Trágica, en el presente trabajo nos proponemos revisar las líneas generales que marcaron las miradas sobre este acontecimiento y sugerir la incorporación de fuentes que pueden contribuir a ampliar el conocimiento disponible hasta el momento.

El balance historiográfico indica que los primeros análisis sobre la Semana Trágica trazaron grandes líneas interpretativas que, en general, no fueron cuestionadas sino a través de ciertos matices. En la actualidad, se suele conceptuar a enero de 1919 como un tema relativamente «agotado». Dentro del campo historiográfico, en cambio, tanto en su vertiente anclada en el movimiento obrero como entre aquellas perspectivas enfocadas en la historia política, cultural y social, los aportes continúan siendo notables y variados. En particular, nos parecen promisorios los nuevos avances sobre la participación de distintos sectores sociales invisibilizados, como las mujeres y los jóvenes; también sobre la comunidad rusa, sus organizaciones y publicaciones; y sobre los distintos niveles del aparato represivo y los servicios de inteligencia. Sostenemos que el estudio de los materiales producidos y recolectados por los espías puede aportar a esta renovación sobre el tema.

Al igual que otros temas vinculados a la historia de los trabajadores, la Semana Trágica de enero de 1919 no ingresó en la historiografía profesional sino hasta luego de varias décadas. Los estudios que hoy consideraríamos clásicos datan de la década del setenta, variando en su aproximación y ponderación sobre los hechos y sujetos. ${ }^{4}$ En un trabajo pionero, Rock (1971/72) definió la huelga general de 1919 como un estallido emocional masivo, sin ninguna coordinación o dirección, engendrado por el odio popular contra la policía. En el mismo momento,

\footnotetext{
${ }^{4}$ Previamente, algunas publicaciones reconstruyeron los hechos: Romariz (1952), ex policía de la Capital Federal, quien participó de la represión; Piñero (1956), otro ex oficial policial; y Babini (1956), basándose en testimonios y documentos recogidos en un seminario de la Unión Cívica Radical. Asimismo, el episodio fue relatado en las llamadas «historias militantes» (Marotta, 1961;Oddone, 1949; Abad de Santillán, 1933).Por último, existieron varias reconstrucciones literarias, una de las más conocidas fue En la semana (Viñas, 1966).
} 
Godio (1985 [1972]) caracterizó el episodio como la huelga general más importante realizada hasta esa fecha, superando los marcos de una acción reivindicativa. Una década más tarde, Bilsky (1984) planteó que se trataba del último momento de una etapa «insurrecionalista» de la clase obrera, la cual ya contenía elementos de una nueva. Por su parte, Iñigo Carrera (2000) interpretó la Semana Trágica como la culminación de un ciclo de lucha obrera por fuera del sistema institucional, aunque sin llegar a ser una insurrección «clásica» (que persigue la conquista del poder político) sino, en todo caso, una insurrección «espontánea». En síntesis, las obras clásicas analizaron los rasgos de confrontación y desborde así como aquellos elementos y dinámicas tendientes a la integración institucional del movimiento obrero. En retrospectiva, la Semana Trágica fue vista como un hito y, en algunos casos, como un punto de inflexión en la dinámica de la clase trabajadora local y en la configuración de otras fuerzas sociales y políticas.

También en el marco de la renovación historiográfica de los años setenta, Solominsky (1971) y Mirelman(1975) abordaron el pogrom contra la población judía del barrio de Once. Posicionados en el campo de los estudios migratorios, estos trabajos incorporaron fuentes inéditas en $i$ dish, ilustrando detalles de la represión así como marcando la persistencia del antisemitismo en importantes sectores de la sociedad. En los ochentas, hubo un crecimiento Durante el crecimiento de los estudios migratorios en los ochenta, hubo varias obras sobre los trabajadores judíos (Avni, 1983; Mirelman, 1988). Las investigaciones posteriores ahondaron en el flujo migratorio transoceánico y las relaciones interétnicas, políticas y culturales (Devoto, 2009; Kahan et al., 2011).

Emparentado con estas pesquisas, Lvovich (2003) estudió las raíces históricas del antisemitismo en Argentina y, en ese marco, analizó la represión estatal y paraestatal de enero 1919 contra la población judía. Como matriz explicativa de su dinámica, utilizó la interpretación del «gran miedo» de Georges Lefebvre. Este trabajo descifró un fenómeno extendido entre los contemporáneos de 1919 y permitió, junto con los estudios de McGee Deutsch (2003) y Rapalo (2012), proyectar una imagen más detallada de la clase dominante, de sus estrategias represivas y sus iniciativas reformistas.

Un destacado aporte reciente fue la compilación hecha por Rot y Glasman (2020), donde varios especialistas revisaron la intervención de los distintos actores sociales y corrientes de izquierda, incluyendo fotografías y documentos poco conocidos. Dentro de este libro, D’Antonio 
(2020) señaló la heterogénea participación de las mujeres, ya fuera como huelguistas, propagandistas y manifestantes, ya fuera como víctimas de la represión, asistentes de los heridos o defensoras de quienes murieron «cumpliendo con su deber». En el último tiempo, varios análisis examinaron la participación femenina e infantil e incorporaron una perspectiva de género. Así, Teitelbaum (2017) revisó las crónicas de una viajera norteamericana y las repercusiones de la represión en Tucumán; y Norando (2019) reflexionó sobre los roles y las relaciones de género para explicar la movilización de la clase trabajadora. Por otro lado, existe una producción relevante fuera del espacio estrictamente académico. Dentro de este amplio universo, Silva (2011) reconstruyó las características del barrio de Nueva Pompeya y de sus residentes, la dinámica de los acontecimientos y el perfil de la Sociedad de Resistencia Metalúrgicos Unidos, que dirigió la huelga en los establecimientos Vasena.

En los últimos años, varios trabajos abordaron el impacto de la Revolución Rusa en las culturas políticas de izquierda yen las derechas (Pittaluga, 2015; Camarero, 2017; Doeswijk, 2013). Sobre este último aspecto, la producción es creciente y diversificada, abarcando sectores dentro del catolicismo, del espectro conservador, el origen de una cultura política de derecha y del anticomunismo militante (entre otros, Devoto, 2002; Gerdes, 2016; López Cantera, 2019).Por otra parte, existe un interés creciente por analizar la represión estatal y la violencia política en el largo plazo y a nivel regional (Franco, 2019; Bohoslavsky y Franco, 2020). A su vez, Lvovich (2020) exploró los archivos diplomáticos y de inteligencia norteamericanos, profundizando la perspectiva del «gran miedo» en clave transnacional, planteada en un artículo previo (Lvovich, 2016). Por su lado, Ablard (2020) también se valió de fuentes poco frecuentes, como los reportes militares estadounidenses o el periódico anarco bolchevique El Soldado Rojo, señalando un aspecto conspirativo y de infiltración represiva dentro de las fuerzas de izquierda; el autor lo destaca como una «pieza faltante» en los análisis.

El libro colectivo Espias y revolución en el Rio de La Plata... (Díaz et al., 2019), del cual participamos quienes aquí escribimos, expuso un conjunto de fuentes sobre el movimiento obrero argentino y uruguayo en la posguerra, provenientes de una red de espionaje internacional a cargo de las embajadas aliadas (Francia, Estados Unidos, Inglaterra e Italia). Este material, si bien no era del todo desconocido, permaneció guardado en los archivos diplomáticos franceses. A partir de su publicación, el equipo se planteó explicar la mirada particular que construían los espías so- 
bre los trabajadores perseguidos. El presente artículo se propone incorporar esta perspectiva al estudio del agitado verano de 1919.

\section{Crisis económica y conflictividad laboral: la situación de la clase obre- ra, 1913-1919}

De temprana conformación y especial combatividad, el movimiento obrero argentino se nutrió desde sus orígenes por la intervención de distintas corrientes: socialista, anarquista y, más tarde, sindicalista revolucionaria y comunista. Durante las primeras décadas del siglo $\mathrm{XX}$, la clase trabajadora se convirtió en protagonista de la realidad política nacional. En retrospectiva, los años posteriores a 1916 jalonaron diversos conflictos laborales que se extendieron in crescendo hasta 1921 inclusive, produciendo uno de los ciclos huelguísticos más agudos de la historia argentina. ${ }^{5}$ La incorporación de los conflictos singulares dentro del concepto de «ciclo» permite mesurar la dinámica social, evitando caer en conclusiones que restringen la activación popular al factor «espontáneo». ${ }^{6}$ Por otro lado, resulta ineludible contextualizar esta agitación social enel marco de la Revolución rusa de 1917, un hecho singular-cuyo alcance, no obstante, «universal»- generó un tembladeral en las estructuras de los estados nacionales, los partidos políticos y las formaciones de clase, recogiendo además la simpatía de un conjunto amplio de trabajadores. ${ }^{7}$

En la ciudad de Buenos Aires, la reactivación económica de posguerra permitió el retorno al trabajo de grandes franjas de la población. La recesión de 1913 había desvalorizado los ingresos populares y elevado el costo de los productos de primera necesidad, con una inflación superior al 150\% (Gerchunoff y Llach, 2010). Ante esta situación, el número de huelgas trepó de 80 en 1916 a 367 en 1919, alcanzando la cifra de paros y huelguistas más alta registrada hasta ese momento. Como una mancha de aceite, las luchas obreras se propagaron y amenazaron, una vez más, con paralizar el tráfico agroexportador en el momento clave de la cosecha estival.

\footnotetext{
${ }^{5}$ Sobre la noción y el contenido del ciclo de conflictividad laboral 1916-1921/1922 puede consultarse: Ceruso (2015); Camarero (2017); Bilsky (1984).

${ }^{6}$ Un ejemplo de esta clase de lecturas podría ser Rock (1971/72).

${ }^{7} \mathrm{Al}$ concluir la Primera Guerra Mundial, se produjeron insurrecciones en Alemania, un gobierno revolucionario en Hungría, ciclo de huelgas en Italia, entre otros. Véase Hobsbawn (2007).
} 
Frente al crecimiento de la conflictividad laboral, la respuesta del gobierno de Hipólito Yrigoyen no fue homogénea. Mientras en algunos casos -marítimos, ferroviarios- su intervención podía ser leída como un apoyo velado a los trabajadores, en otros, en cambio, reprimió con dureza -frigoríficos, municipales-. ${ }^{8}$ La elite social veía al gobierno surgido de la aplicación de la ley Sáenz Peña como plebeyo y ajeno a su dominio, desconfiaba de sus posiciones «obreristas» y de su capacidad de contener la situación. Desde un comienzo, Yrigoyen había cosechado fuertes enemistades por sostener una política de neutralidad durante la guerra. Se lo acusaba de germanófilo-incluso, de potencial conspirador leninista-, situación quese agravó con el hundimiento de los buques de bandera nacional y del ingreso de Estados Unidos -y otros países americanos- en la conflagración.

De manera que, bordeando el final de la «Gran Guerra», el clima social y político estaba convulsionado. En las facultades, el movimiento estudiantil «reformista» se amplificaba como una poderosa corriente de opinión hacia el resto del continente latinoamericano. A finales de 1918, una huelga de policías en la ciudad de Rosario apuntaló el malestar contra el gobierno, encendiendo las alarmas entre la clase dominante. Si quienes debían guarecer el orden civil lo quebraban, entonces los privilegios y el respeto por la propiedad privada también podían diluirse. La revolución soviética no sólo se mostraba como un experimento en tiempo real sino que confirmaba la posibilidad fáctica de un cambio profundo del orden vigente. Para unos, resultó una fuente de inspiración; para otros, una verdadera pesadilla. De este modo, se podría pensar que la Semana Trágica de enero de 1919 se desenvolvió sobre temores que ya sobrevolaban a la clase dominante, reforzados por el despliegue de un ciclo huelguístico y organizativo excepcional del movimiento obrero, en un contexto internacional de posguerra también conmocionado de forma inédita.

\section{Los hechos: una lectura posible}

A principios de diciembre de 1918 se inició una huelga en los talleres Vasena, una de las empresas metalúrgicas más grandes del país, cuya

\footnotetext{
${ }^{8}$ Sobre las posiciones «obreristas» del gobierno de Yrigoyen, véase Rock (1977) y Falcón y Montserrat (2000).
} 
fábrica y depósito se localizaban en los barrios obreros de San Cristóbal y Nueva Pompeya, respectivamente. El reclamo pretendía recomponer las condiciones laborales, afectadas por la crisis económica. Entre los animadores del conflicto se encontraba la Sociedad de Resistencia Metalúrgicos Unidos, de orientación anarquista y enrolada en la FORA V Congreso, controlada por esa misma tendencia. Frente al pedido obrero, la patronal contrató rompehuelgas y vigilancia propia, sumando además efectivos policiales.

Al cabo de un mes, la situación en los talleres de Nueva Pompeya alcanzó un elevado grado de tensión. A principios de enero, hubo varios choques entre los huelguistas y las fuerzas represivas; en uno de ellos, el día 6, murió un cabo de policía. Algunas versiones sugieren que los hechos posteriores formaron parte de una revancha policial. Al día siguiente, cuatro trabajadores murieron y una veintena resultó herida durante un tiroteo. ${ }^{9} \mathrm{El}$ miércoles 8 , distintos gremios abandonaron el trabajo y convocaron, junto con la FORA V, a una huelga general. El crimen despertó la solidaridad del barrio, que se movilizó en masa a velar a las víctimas. En simultáneo, un conflicto en el sector marítimo amenazaba extenderse a todo el país, enfrentando al empresariado naviero, que reclamaba la intervención gubernamental para garantizar la «libertad de trabajo», es decir, la contratación irrestricta de personal en detrimento del closed shop establecido por los trabajadores marítimos. ${ }^{10}$

El 9, por la tarde, comenzó a sentirse la parálisis en varios gremios de la ciudad. En pocas horas, sin embargo, los hechos se precipitaron con velocidad. Una multitud acompañó los restos de las víctimas hasta el cementerio de Chacarita. En el camino, el cortejo fúnebre atravesó varios incidentes violentos y, al llegar, fue duramente atacado por la policía. La jornada tuvo otros eventos poco esclarecidos, como el incendio de la iglesia Jesús Sacramentado, el tiroteo en el Departamento Central de Policía o el sitio a los empresarios reunidos en la fábrica Vasena. Ese mismo día, ya fuera por pánico o de forma preventiva, se ordenó el acuartelamiento de la policía y la militarización de la ciudad con fuerzas

\footnotetext{
${ }^{9}$ «Agitación obrera. La huelga de metalúrgicos. El choque sangriento de ayer. Cuatro muertos y veinte heridos», La Nación, 08/01/1919; «Huelga Vasena. Otro choque violento», El Pueblo, 6,7 y 8/01/1919.

${ }_{10}$ «Acontecimientos revolucionarios en Buenos Aires», Correspondencia política y comercial. América. No 4, fecha 14 de enero de 1919, en Dossier no 106 de la red FABI, «Question ouvrière», sección política 132PO/2, Argentina 1918-1920, de los Archives du Ministère des Affaires Étrangères, en Nantes, Francia, citado en Díaz et al. (2019).
} 
del ejército regular; aún no queda claro si esas decisiones partieron del Poder Ejecutivo o fueron órdenes autónomas de los mandos jerárquicos de las fuerzas. ${ }^{11}$ Junto con la policía y los bomberos, las tropas sumaban 10.000 efectivos. Desde este momento, la violencia represiva no cesó decrecer. En los días venideros, Buenos Aires se transformó en un escenario dominado por los asaltos sobre locales sindicales, las razzias en los barrios proletarios, los incendios de tranvías y comisarías, los combates callejeros y la censura sobre el periodismo.

Durante los días 10 y 11, la huelga general alcanzó su punto máximo y la represión se intensificó, desarrollándose «la caza del hombre»: fuerzas militares, policiales y grupos civiles atacaron a las familias en los barrios obreros, asesinando a centenares de hombres, mujeres y niños y deteniendo a otros miles. ${ }^{12}$ Las cifras totales de muertos resultan todavía un enigma. Según diversos testimonios, la cantidad de víctimas fatales oscilaría entre 60 y 1356, los heridos sumarían entre 150 y 5000 y los detenidos habrían superado los 5000, sólo en la Capital Federal. ${ }^{13}$ Un informe para la embajada francesa notificaba que, pese a no haberse liberado a los presos, «la represión ha sido tal que los huelguistas no insistieron. La policía masacró de manera salvaje todo lo que fuera o pasara por ruso» y agregaba que «los rusos son los únicos extranjeros que no tienen, de hecho, protección posible». ${ }^{14}$

Del lado del aparato represivo, las bajas fueron escasas, lo cual indicaría que los enfrentamientos durante los primeros días de la huelga fueron, en realidad, reyertas aisladas o esfuerzos de auto-defensa por parte de sectores civiles. ${ }^{15}$ De igual modo, las afirmaciones sobre un connato revolucionario se demostraron falsas. No existió el «soviet de Bue-

\footnotetext{
${ }^{11}$ Para una discusión acerca del rol de Dellepiane y los rumores sobre un complot contra el presidente Yrigoyen, véase Bilksy (1984) y Rock (1977).

12 «Acontecimientos revolucionarios en Buenos Aires», Correspondencia política y comercial. América. $N^{\circ} 4$, fecha 14 de enero de 1919, en Dossier n ${ }^{\circ} 106$ de la red FABI, «Question ouvrière», sección política 132PO/2, Argentina 1918-1920, de los Archives du Ministère des Affaires Étrangères, en Nantes, Francia, citado en Díaz et al. (2019).

${ }^{13}$ Véase Bilsky (1984); Romariz (1952); «Los crímenes del Estado», La Protesta, 23/01/ 1919.

14 «Acontecimientos revolucionarios en Buenos Aires», Correspondencia política y comercial. América. No 4, fecha 14 de enero de 1919, en Dossier no 106 de la red FABI, «Question ouvrière», sección política 132PO/2, Argentina 1918-1920, de los Archives du Ministère des Affaires Étrangères, en Nantes, Francia, citado en Díaz et al. (2019).

${ }^{15}$ Las víctimas en las fuerzas armadas habrían sido nueve heridos y cuatro muertos (Romariz, 1952, p. 176).
} 
nos Aires» así como tampoco emergió una fuerza política que direccionara globalmente la movilización. Antes bien, el conjunto de las corrientes políticas se esforzó por lograr un pronto desenlace, con excepción de los sectores libertarios y de la izquierda socialista. Sobre la participación del anarquismo en los sucesos, existen ciertas diferencias entre los autores. Sin duda, es difícil generalizar su participación en los hechos; no obstante, se destaca la acción de la Sociedad de Resistencia Metalúrgicos Unidos y la FORA V mientras que, de forma colateral, aparece la agitación desarrollada desde La Protesta y los periódicos pro-bolcheviques Bandera Roja y El Burro.

En contraste, la FORA IX se sumó al conflicto recién el día 9. Después de la emboscada policial en el cementerio de Chacarita, donde dirigentes de la central participaron como oradores, el Consejo Federal se reunió por la noche y definió ponerse a la cabeza de la huelga. El impulso que dio al movimiento los días 10 y 11 fue muy importante, aunque varios autores destacan que su intervención estuvo dirigida a reencauzar el conflicto. En efecto, una comisión de la FORA IX entregó el pliego de reivindicaciones al general Dellepiane, se reunió con el ministro del Interior y con el presidente Yrigoyen. Bajo una mayoría sindicalista, la central buscó una salida pronta de la huelga y definió centrar el reclamo, por un lado, en la resolución del conflicto en la empresa Vasena y, por el otro, en la libertad de los presos, relegando el pedido de derogación de la ley de residencia o la jornada laboral de ocho horas.

El Partido Socialista (PS) llamó durante la noche del 10 a concluir la medida, señalando la desnaturalización del movimiento causada por «factores externos» a la organización sindical. La sola expresión no parecía distar demasiado de los «elementos revolucionarios» o «factores de desorden», mencionados en los informes de la legación francesa. ${ }^{16} \mathrm{El}$ Partido Socialista Argentino, dirigido por Alfredo Palacios, también propuso levantar la medida. La fracción izquierdista recién separada del PS, el Partido Socialista Internacional, aunque apoyaba la continuidad de la lucha obrera y no cuestionaba los «excesos» en la lucha, acató el llamado a concluir la huelga que hizo la FORA IX, en la que participaba en minoría (Camarero, 2017).

Según vimos en la primera parte, los estudios sobre la Semana Trágica han señalado una relación intrínseca entre el miedo a la extensión local de la revolución bolchevique y la envergadura de la represión

${ }^{16}$ «Acontecimientos revolucionarios en Buenos Aires», op. cit. 
que tuvo lugar durante el mes de enero. Como una suerte de profecía autocumplida, los sucesos del verano de 1919 habrían vuelto tangible la creencia compartida entre los sectores dominantes acerca del carácter revolucionario de los acontecimientos en curso. Antes del estallido de la huelga, en muchos cuarteles y embajadas corrían rumores acerca de un complot «maximalista», organizado por simpatizantes de los levantamientos comunistas europeos.

El día 12 de enero, el red scare alcanzó su punto cúlmine con el descubrimiento del «soviet de Buenos Aires», siendo detenidos el periodista judío de izquierda, Pinnie Wald, su compañera y otros militantes. En paralelo, se desarrollaba la acción de las guardias blancas, integradas por jóvenes y miembros prominentes de la aristocracia porteña y del partido radical. Para este sector, el peligro rojo convirtió a «maximalista», «bolchevique», «ruso» o «judío» en sinónimos. En suma, el accionar represivo tuvo un carácter brutal sobre determinados grupos: los militantes, sobre todo anarquistas; los barrios obreros, en especial San Cristóbal y Pompeya; la comunidad judía, en particular aquella asentada en el ghetto a cielo abierto del barrio de Once.

\section{Espías, mouchards y la presencia de los rusos}

La red FABI (por sus siglas en inglés), articulada por las embajadas de los países aliados -Francia, Italia, Estados Unidos e Inglaterra-, surgió en el contexto de la Primera Guerra Mundial con el objetivo de rastrear la actividad alemana en la región. Una vez finalizada la contienda bélica, la red se reorientó hacia el espionaje político y sindical de militantes y organizaciones «maximalistas», término que entremezclaba de forma imprecisa a libertarios con socialistas de izquierda y simpatizantes del gobierno soviético.Las diferencias ideológicas no ocupaban un lugar relevante; en última instancia, todos estaban confabulados o terminarían entendiéndose (Díaz et al., 2019).

Es probable que la redefinición de objetivos de FABI haya estado motivada por la información circulante entre las legaciones sobre un complot para asesinar al presidente de Estados Unidos y a los primeros ministros de Francia y Gran Bretaña, mientras se firmaban los tratados de paz. Otros informes alertaban sobre inminentes huelgas en los principales puertos de países aliados (Lvovich, 2020). Un comunicado fechado en 1918-que hoy resulta hilarante-alertaba sobre la presencia de Le- 
nin en España, reclutando adherentes para una revolución que sería secundada por 700 españoles enviados desde Argentina (Díaz et al., 2019, p. 33). Esta clase de datos constituyeron una fuente prolífica que permite analizar ciertos imaginarios de los organismos represivos, los cuales permearon la llamada opinión pública e influyeron sobre el estado de ánimo de la burguesía. Con este tipo de materiales, la tarea del investigador consiste en separar los rasgos fantasiosos de los informes y recuperar aquellos datos que podrían ser verosímil.

En el poco tiempo que duró la actividad registrada -menos de dos años- la red FABI elaboró documentos de diverso tipo, incluyendo un listado de los 400 militantes «más peligrosos». Llamativamente -O no, quedaron afuera de esta vigilancia las centrales sindicales, tanto la anarquista como la sindicalista, y el Partido Socialista, considerado como un «partido del orden». Las organizaciones obreras tampoco fueron objeto de atención, aunque sí algunas de importancia, como la Federación Obrera Marítima (Díaz et al., 2019, pp. 65-67).Por el contrario, amerita especial atenciónla abundante presencia en el listado de individuos «rusos», muchos de ellos también judíos. ${ }^{17}$ Por otro lado, la red hizo persiguió algunos periódicos anarquistas pro-bolcheviques como El Burro, Bandera Roja, Renovación y Barricada.

Quizás uno de los principales puntos de contacto entre estas publicaciones fuera el énfasis puesto en el cambio social mediante una insurrección armada, factor que adquirió un relieve mayor con el juicio realizado por el estado argentino en mayo de 1919 a los redactores $-\mathrm{y}$ grupo fundador- de Bandera Roja, Enrique García Thomas, Atilio Biondi y Hermenegildo Rosales, condenados y enviados al penal de Ushuaia (Díaz et al., 2019, pp. 43-47; Doeswijk, 2008-2009). ${ }^{18} \mathrm{La}$ agrupación nucleaba militantes anarquistas disidentes con La Protesta y cosechaba amplias simpatías hacia la revolución bolchevique, hallándose próxima a organizaciones obreras rusas, que estaban bajo vigilancia. El grupo estaba vinculado además a la Liga de Educación Racionalista e intervenía gremialmente entre los trabajadores de frigoríficos, del transporte y del campo. Si bien Bandera Roja empezó a publicarse en abril 1919, un informe de la red FABI de diciembre de 1918 señalaba que agrupaciones de Campana

\footnotetext{
${ }^{17}$ No resulta sencillo medir cuántos judíos y rusos había en la Argentina. Sobre las cifras migratorias, véase Avni (1983, pp. 533-535).

${ }^{18}$ Según se nos ha informado en el archivo judicial, el expediente de este caso fue destruido luego de haberse cumplido 30 años de su última actuación procesal.
} 
y Capital Federal conformarían un diario anarquista «con perspectiva abiertamente revolucionaria a la soviet». ${ }^{19}$

El enemigo de la red FABI era difuso y abarcaba un espectro amplio de acción. Uno de los informes afirmaba que los «bolcheviques pueden estar seguros de contar con el apoyo de todos los anarquistas y no hay que olvidar que estos son muy numerosos en Argentina». ${ }^{20}$ En cierto modo, esta suerte de «hipótesis de guerra» podría explicar por qué cuatro potencias imperialistas, así como los estados argentino y uruguayo, dedicaron importantes esfuerzos para su vigilancia y represión. A fines de diciembre de 1918, la legación argentina en Uruguay comunicó las medidas tomadas por aquel gobierno para reprimir cualquier agitación en el movimiento obrero oriental. El informe indicaba que, desde la huelga de policías en Rosario, se notaba una «sorda pero intensa» agitación de «cabecillas ácratas»-identificados como rusos y españoles- sobre la fuerza policial. Al final, señalaba que «los rusos son expresamente vigilados, pues como es sabido, buena parte de ellos están afiliados asociedades terroristas, o propagan con fanático ardimiento, las doctrinas maximalistas». ${ }^{21}$

En efecto, los «rusos» constituían una minoría social en términos numéricos, aunque significativa en el plano político; según el Censo Nacional de 1914, la población de este origen apenas alcanzaba las 100.000 personas, concentrado un tercio en la Capital Federal. ${ }^{22} \mathrm{La}$ emigración rusa comenzó a principios del siglo XX, a partir de la multiplicación de los pogroms del zarismo, la guerra ruso-japonesa de 1904 y la derrota de la revolución rusa de 1905. Así, no pocos integrantes de esta comunidad habían hecho sus primeras armas en las organizaciones clandestinas de su país natal. Hacia 1919, los militantes rusos en Buenos Aires se nucleaban en torno al Comité de Ayuda a los Diputados Obreros, Soldados y Campesinos (pro-bolchevique, luego renombrada Unión Obrera Socialista Rusa) y alrededor del grupo que dio vida a la Federación de Organizaciones Obreras Rusas de Sudamérica, surgida entre fi-

\footnotetext{
19 «Banderas Rojas», 23/12/1918, Dossier no 106 de la red FABI, «Question ouvrière», sección política 132PO/2, Argentina 1918-1920, de los Archives du Ministère des Affaires Étrangères, en Nantes, Francia, citado en Díaz et al. (2019).

${ }^{20}$ Nota escrita por ITA, 9/12/18,Dossier n ${ }^{\circ} 106$ de la red FABI, «Question ouvrière», «, sección política 132PO/2, Argentina 1918-1920, de los Archives du Ministère des Affaires Étrangères, en Nantes, Francia, citado en Díaz et al. (2019).

${ }^{21}$ «Informe al Ministro de Relaciones Exteriores y Culto», Archivo General de la Nación, Series Históricas, Ministerio del Interior, Carpeta 30, 28/12/1918.

${ }^{22}$ Véase Tercer Censo Nacional (1914).
} 
nes de 1917 y comienzos de 1918,publicando el periódico Golos Trudá. Además, recordemos que estos grupos de exiliados rusos establecieron los primeros vínculos con la URSS, hacia 1920 (Camarero, 2017, p. 199). En esta dirección, entre noviembre y diciembre de 1918, se realizaron en Buenos Aires varios actos de adhesión y simpatía hacia la Revolución contemporánea.

Interesa señalar quela lectura sobre los informes de la red no permite desprender ningún resquemor especial hacia el pueblo judío. Antes bien, podríamos afirmar que, con frecuencia, la comunidad judía fue subsumida bajo la categoría de «rusos». Por ejemplo, dentro de un listado de «centros maximalistas» se incluía al Club Maximalista Judío, sito en Paso 131 (corazón del barrio del Once, donde también tenía su sede la Liga Racionalista Judía) y se informaba del periódico Pan y Libertad, del que no se sabía si estaba escrito en ruso o en idish. ${ }^{23}$ Sin embargo, no eran mencionadas organizaciones de la izquierda judía que fueron objeto de la violencia antisemita, como Avangard, Poalei Sión o la Asociación Israelita de Actores (Bilsky, 1984).

Una de las características atribuidas al enemigo ruso-bolche-maximalista era su dominio de los explosivos químicos y las armas. En un informe del attaché italiano, fechado el 2 de diciembre de 1918, se afirmaba que el acto realizado por la comunidad rusa el 24 de noviembre tenía la intención de transformarse en una revolución, pero que fracasó porque «no llegaron las armas». ${ }^{24}$ Un parte del 13 de enero de 1919 reconocía que las únicas armas con que contaba la defensa de los locales eran las requisadas en las armerías ese mismo día y añadía «no había explosivos porque el ruso que había prometido llevar las bombas nunca apareció» (Díaz et al., 2019, p. 34).Otro informe poco creíblealertaba sobre ametralladoras halladas «en la zona de Ayacucho y Ombú», en el barrio judío del Once. ${ }^{25}$

\footnotetext{
${ }^{23}$ Informe de ANA, 7/1/1919, Dossier no 106 de la red FABI, «Question ouvrière», sección política 132PO/2, Argentina 1918-1920, de los Archives du Ministère des Affaires Étrangères, en Nantes, Francia, citado en Díaz et al. (2019).

${ }^{24}$ Según la fuente: «Se me asegura que los maximalistas rusos de aquí están admirablemente organizados y que bastará un signo de sus jefes para que bajen armados a las calles».Informe de ITA, 2/12/1918, Dossier n ${ }^{\circ} 106$ de la red FABI, «Question ouvrière», sección política 132PO/2, Argentina 1918-1920, de los Archives du Ministère des Affaires Étrangères, en Nantes, Francia, citado en Díaz et al. (2019).

25 «Movimiento revolucionario huelguista», 12/1/1919, Dossier $n^{\circ} 106$ de la red FABI, «Question ouvrière», sección política 132PO/2, Argentina 1918-1920, de los Archives du Ministère des Affaires Étrangères, en Nantes, Francia, citado en Díaz et al. (2019).
} 
En enero de 1919, la comunidad rusa fue atacada como parte de una reacción general contra los agitadores extranjeros en el movimiento obrero y no únicamente por su condición de judíos. Como vimos, ruso, maximalista o judío funcionaban como representaciones superpuestas, atribuidas a distintos actores. Sin embargo, «ruso» no era idéntico a «judío»; en este punto, el desplazamiento semántico no debe omitir la densidad del entramado organizativo gremial y político de la comunidad migrante, sumado a la relación inevitable con el proceso revolucionario soviético, el cual era activamente apoyado. A su vez, es cierto que tanto catalanes como judíos-rusos eran identificados desde la primera década como los máximos representantes de la subversión (Moya, 2004). Así, el embajador Stimson mencionaba que, del93 cuerpos identificados en enero de 1919, 14 pertenecían a catalanes y 179, a rusos (Mirelman, 1975 , p. 65).

Estos estereotipos no habían surgido en esta coyuntura sino que venían de lejos. Ambas comunidades migrantes tenían destacados cuadros políticos y sindicales, participantes en un sinfín de organizaciones gremiales, mutuales, culturales. Más aún, el intento de magnicidio contra Quintana (1906) o el asesinato del jefe de policía Falcón (1909) fueron llevados a cabo, en un caso, por un tipógrafo anarquista de origen catalán (Salvador Planas) y, en el otro, por un joven ácrata y ruso (Simón Radowitzky).Estos atentados, junto con el miedo internacional a la violencia ácrata, contextualizaron la profesionalización de la policía porteña desde comienzos del siglo XX y, luego, la modernización de las fuerzas armadas durante el gobierno de Yrigoyen, especialmente relativa a la inteligencia militar y la represión sobre el movimiento obrero (Galeano y Albornoz, 2016; Rot, 2020).

En este plano, las fuentes diplomáticas permiten al menos cuestionar estos avances, trasluciendo una desconfianza hacia las fuerzas represivas argentinas. Podríamos concluir que, a la par de las redes, flujos e intercambios militantes en una escala global, la articulación de esfuerzos represivos también se estructuró de forma transnacional, compartiendo métodos, técnicas así como fichas de sospechosos, con fotografías y huellas dactilares. La colaboración represiva multilateral, finalmente, escogió en 1920 la ciudad de Buenos Aires para realizar una conferencia sudamericana de policías. 


\section{Conclusión}

La Semana Trágica se ha instalado en el campo historiográfico como un episodio clave de la historia nacional y sobre el cual sobrevolaba la idea de que todo estaba dicho. Sin embargo, en los últimos años se han producido algunos aportes relevantes en cuanto a las perspectivas de análisis. Los avances se verificaron en aquellos sub-campos especializados en la interseccionalidad étnica, la historia política y, en menor medida, los estudios de género. En otros casos, se ha revisado documentación diplomática poco explorada, que entroncó con una mirada transnacional.

Según vimos, tras la recesión de 1913 y el impacto de la Primera Guerra Mundial, la reactivación económica contextualizó un ciclo de conflictividad huelguística dentro del cual se inscribió la Semana Trágica de Buenos Aires. En este marco, puede comprenderse la redefinición de objetivos de espionaje de la red FABI hacia la persecución de «rusosmaximalistas», así como algunos de sus informes, trasluciendo un ánimo general enrarecido y que podría convulsionarse aún más. En esta dirección, el re-examen sobre los hechos de enero de 1919 permitió pensar que la envergadura de la masacre represiva no respondió a una amenaza real aunque sí, quizás, potencial.

Los datos indican que los escasos «enfrentamientos» fueron, en lo concreto, intentos de autodefensa por parte de sectores populares desarmados y, en parte, desorganizados. Este factor no invalida, sin embargo, la existencia de agrupaciones referenciadas con la Revolución Rusa y con la vía insurreccional en tanto perspectiva posible para la emancipación social, como fue el caso de Bandera Roja, clausurada y enjuiciada por el estado en mayo de 1919. Según hemos señalado, los informes de la red FABI se enfocaron solo en determinadas fuerzas políticas, cuyas diferencias además se estimaban como secundarias en cuanto que, desde su perspectiva, prevalecerían aquellos elementos comunes a una lucha general -y violenta- contra el capitalismo. Un caso particular fue el seguimiento de los rusos, reputados -al igual que los catalanes-como terroristas peligrosos, con dominio de las armas y explosivos así como, en general, adherentes al proceso soviético.

En cuanto al rol de las principales organizaciones obreras y las izquierdas, observamos que estas buscaron encausar la movilización hacia una negociación con el gobierno, con escasas excepciones. Por otro lado, la documentación visitada plantea incorporar al análisis de la acción 
represiva otras formas de desactivación del conflicto. Al respecto, las fuentes señalan que, por un lado, Yrigoyen negoció con Vasena financiar el aumento salarial solicitado por los trabajadores mediante una reducción impositiva mientras que, por el otro, se comprometió ante el comité de huelga a liberar a los presos, lo que finalmente no sucedió.

Por último, dada la riqueza de la documentación cotejada en este artículo, proveniente de los archivos franceses, es factible pensar que nuevas indagaciones deberían explorar los acervos de los otros países, incluso más allá de los aliados y la red FABI. Este trabajo intentó aportar nuevos elementos para pensar las preguntas clásicas sobre el acontecimiento y plantear otras nuevas, entrelazando la historia social con el análisis sobre el punto de vista del espionaje estatal. Será motivo de futuras indagaciones profundizar esta ligazón.

\section{Referencias bibliográficas}

Abad de Santillán, D. (1933). La FORA. Ideología y trayectoria del movimiento obrero revolucionario en la Argentina. Buenos Aires, Argentina: Nervio.

Ablard, J. (2020). Counter-revolution without revolutionaries: Conspiracy in the Argentine Barracks, 1919-1930. A Contracorriente: una revista de estudios latinoamericanos, 17(3), 173-207.

Albornoz, M. y Galeano, D. (2016).El momento Beastly: la policía de Buenos Aires y la expulsión de extranjeros (1896-1904).Astrolabio, (17), 6-41.

Avni, H. (1983). Argentina y la historia de la inmigración judia (18101950). Buenos Aires, Argentina: Editorial Universitaria Hebrea de Jerusalem-AMIA.

Babini, N. (1956).Enero de 1919, los hechos y los hombres de la Semana Tragica. Buenos Aires, Argentina: S.E.P.A.

Bilsky, E. (1984). La semana trágica. Buenos Aires, Argentina: Centro Editor de América Latina.

Bohoslavsky, E. y Franco, M. (2020). Elementos para una historia de las violencias estatales en la Argentina en el siglo XX. Boletín del Instituto de Historia Argentina y Americana «Dr. Emilio Ravignani», (53), 205-227. 
Camarero, H. (2017). Tiempos rojos. El impacto de la Revolución rusa en Argentina. Buenos Aires, Argentina: Sudamericana.

Ceruso, D. (2015). La militancia obrera industrial en el lugar de trabajo, 1916-1943, Buenos Aires, Argentina: Imago Mundi.

Devoto, F. (2002). Nacionalismo, fascismo y tradicionalismo en la Argentina moderna: una historia. Buenos Aires, Argentina: Siglo XXI Iberoamericana.

Devoto, F. (2009). Historia de la inmigración en la Argentina. Buenos Aires, Argentina: Sudamericana.

Díaz, H. (Comp.). (2019).Espionaje y revolución en el Río de la Plata. Los archivos de una red diplomática de persecución al maximalismo (19181919). Buenos Aires, Argentina: Imago Mundi.

Doeswijk, A. (2008-2009). Bandera Roja, diario anarco-bolchevique. Politicas de la Memoria, (8-9), 261-269.

Doeswijk, A. (2013). Los anarco-bolcheviques rioplatenses. Buenos Aires, Argentina: Cedinci.

Falcón, R. y Montserrat, A. (2000). Estado, empresas, trabajadores y sindicatos. En Falcón, R. (Ed.). Nueva Historia Argentina VI. Democracia, conflicto social y renovación de ideas (1916-1930). Buenos Aires, Argentina: Sudamericana.

Franco, M. (2019). El estado de excepción a comienzos del siglo XX: de la cuestión obrera a la cuestión nacional. Avances del Cesor, 16(20), 29-51.

Gerchunoff, P. y Llach, L. (2010). El ciclo de la ilusión y el desencanto. Un siglo de politicas económicas argentinas. Buenos Aires, Argentina: Planeta.

Gerdes, T. (2016)La Semana Trágica y la perspectiva del catolicismo social sobre la cuestión social en el Río de la Plata, 1880-1919, Villa María, Argentina: Eduvin.

Godio, J. (1985). La semana trágica de enero de 1919. Buenos Aires, Argentina: Hyspamérica [1972].

Hobsbawn, E. (2007). Historia del siglo XX. Buenos Aires, Argentina: Crítica.

Iñigo Carrera, N. (2000).La estrategia de la clase obrera 1936. Buenos Aires, Argentina: La Rosa Blindada-PIMSA.

Kahan, E., Schenquer, L., Setton, D. y Dujovne, A. (Comp.) (2011).Mar- 
ginados y consagrados. Nuevos estudios sobre la vida judía en la Argentina. Buenos Aires, Argentina: Lumiere.

López Cantera, M. (2019). Orígenes y consolidación del anticomunismoen Argentina (1917-1943). Tesis de Doctorado, Facultad de Filosofía y Letras, Buenos Aires, Argentina.

Lvovich, D. (2003). Nacionalismo y antisemitismo en la Argentina. Buenos Aires, Argentina: Javier Vergara.

Lvovich, D. (2016). La semana trágica en clave transnacional. Influencias, repercusiones y circulaciones entre Argentina, Brasil, Chile y Uruguay, 1918-1919. En Bertonha, J. y Bohoslavsky, E. (Comps.). Circule por la derecha. Percepciones, redes y contactos entre las derechas sudamericanas, 1917-1973. Buenos Aires, Argentina: UNGS.

Lvovich, D. (2020). El Gran Miedo de 1919 a escala global: la Semana Trágica argentina y los archivos norteamericanos. Estudios, (43), 159-172.

Marotta, S. (1961). El movimiento sindical argentino. Buenos Aires, Argentina: Lacio.

Mcgee Deutsch, S. (2003). Contrarrevolución en la Argentina, 1900-1932. La Liga Patriótica Argentina. Buenos Aires, Argentina: UNQUI.

Mirelman, V. (1975).The Semana Trágica of 1919 and the jews in Argentina. Jewish Social Studies, (37), 61-73.

Mirelman, V. (1988). En búsqueda de una identidad. Los inmigrantes judios en Buenos Aires 1890-1930. Buenos Aires, Argentina: MiláAMIA.

Moya, J. (2004). The positive side of stereotypes: Jewish anarchists in early-twentieth-century Buenos Aires. Jewish History, (18), 19-48.

Norando, V. (2019). La ciudad arde este verano. Buenos Aires: enero de 1919. Roles sexuales y demandas por derechos de una clase obrera generizada. Secuencia, (105), 1-25.

Oddone, J. (1949). Gremialismo proletario argentino. Buenos Aires, Argentina: La Vanguardia.

Piñero, O. (1956).Los orígenes y la trágica semana de enero de 1919. Buenos Aires, Argentina: s/e.

Pittaluga, R. (2015). Soviets en Buenos Aires. La izquierda de la Argentina ante la revolución en Rusia. Buenos Aires, Argentina: Prometeo.

Rapalo, M. (2012). Patrones y obreros. La ofensiva de la clase propietaria, 
1918-1930. Buenos Aires, Argentina: Siglo XXI.

Rock, D. (1971/72). Lucha civil en la Argentina. La Semana Trágica de Enero de 1919. Desarrollo Económico, (42-44), 165-215.

Rock, D. (1977). El radicalismo argentino, 1890-1930. Buenos Aires, Argentina: Amorrortu.

Romariz, J. (1952). La semana trágica, Antecedentes sociales, económicos y políticos. Episodios y relatos históricos de los sucesos sangrientos de enero de año 1919, en la Capital Federal. Buenos Aires, Argentina: Hemisferio.

Rot G. y Glasman, L. (Coord.) (2020). Entre la revolución y la tragedia. Fotografias, documentos y miradas sobre la Semana Trágica. Buenos Aires, Argentina: El Topo Blindado.

Silva, H. (2011). Días rojos, verano negro. Enero de 1919, la Semana Trágica de Buenos Aires. Buenos Aires, Argentina: Terramar.

Solominsky, N. (1971). La Semana Trágica en la Argentina. Buenos Aires, Argentina: Biblioteca popular judía.

Teitelbaum, V. (2017). Protestas, derechos y violencias en enero de 1919 en Argentina. Una reflexión a partir del libro de viajes de Katherine Dreier y de la prensa.Cuadernos del CIESAL, (16), 186 - 207.

Viñas, D. (1966). En la semana. Buenos Aires, Argentina: Jorge Álvarez. 